\title{
Knowledge's and Attitude of Parents about Epileptic Disease among Their Children at Assuit University Hospital
}

\author{
Hiam H Mohamed, Ghaydaa A Shehata, Safaa Ahmed Kotb \& Soad A Shrkawy. \\ Nursing Specialist at Assuit University Hospital Assiut University, Egypt. \\ Professor of Neurological Medicine, Faculty of Medicine Assiut University, Egypt. \\ Assistant professor of Community Health Nursing, Faculty of Nursing Assiut University, Egypt.
}

\begin{abstract}
Epilepsy is one of the most common chronic neurological disorders that affect approximately 70 million people worldwide. Nearly $80 \%$ of people with epilepsy are found in developing countries. Aim: This study was designed to assess knowledge and attitude of parents about their epileptic children in the outpatient neurological clinic. Design: A descriptive cross-sectional research design study was applied among parents who visited the outpatient neurological clinic at Assuit University Hospital. The sample included 400 parents, who were selected randomly. Methodology An interview questionnaire studied form was developed by the researchers for the collection of data concerning socio demographic data and parents' knowledge and attitude regarding epilepsy.

Results: More than two thirds of the children $(67.25 \%)$ had a positive family history. Concerning the total score of parent's knowledge about epilepsy $(71.9 \%)$ of them had a poor score, The present study revealed that $(85 \%)$ of them had a negative attitude towards epilepsy. Conclusion: The current study found that a significant difference between parents' knowledge and attitudes as regarding epilepsy.Recommendations: Application of continuous health education programs for parents in different grades with emphasis primary health care services especially epileptic children care to improve the parents' knowledge and attitude.
\end{abstract}

\section{Keywords: Knowledge's, Attitude, Epilepsy \& Children Parents.}

\section{Introduction}

Epilepsy is characterized by a long-term risk of recurrent seizures. Epilepsy accounts for $27 \%$ of all the neurological diagnoses associated with a substantial burden on physical and mental health. Approximately $70 \%$ of children who suffer from epilepsy during their childhood eventually outgrow it. There are also some seizures, such as febrile seizures, that are one-time occurrences during childhood, and they do not result in permanent epilepsy (Duncan et al., 2009, Back, 2011 and WHO, 2014).

The prevalence of childhood epilepsy in Upper Egypt Al kharge District \& Al Quseir City in both sexes is 9.7 per 1000 , males 5.6 per 1000 , females 4.1 per 1000 Farghley et al., (2012 ) At Assiut University Children Hospital, between 2012 and 2013, the total number of epileptic children (males and females) is 600 according to the hospital statistics records Hospital Statistics Records, (2012-2013) In ElMinia City, Egypt, it was estimated that the prevalence of epilepsy was 7-10/1000 among school children below the age of 15 years. Also it was estimated epilepsy was higher in boys than in girls (Hamdy, 2010).

The etiology of the epilepsy according to age; The most common causes of seizure disorder during the first 6 months of life are severe birth injury, congenital defects involving the Central Nervous
System (CNS), infections, and inborn errors of metabolism. In patients between 2 and 20 years of age, the primary causative factors are birth injury, infection, trauma, and genetic factors. In individuals between 20 and 30 years of age, seizure disorder usually occurs as the result of structural lesions, such as trauma, brain tumors, or vascular disease. Although many causes of seizure disorders have been identified, three fourths of all seizure disorder cannot be attributed to a specific cause and are considered idiopathic (Lewis et al., 2008).

Epilepsy is characterized by a long-term risk of recurrent seizures (Duncan, 2009) These seizures may present in several ways depending on the part of the brain involved and the person's age (National Institute for Health, 2012).

Physical complications, systematic complications ,Psychiatric complications and cognitive dysfunction are the most common problems related to the epilepsy and these affected by the etiology, age of onset, seizure type, frequency of occurrence, and success of treatment. An epileptic seizure can cause severe physical injuries, burns, hypoxia and drowning due to respiratory arrest and aspiration. The mortality rate for those with epilepsy is 2-5 times higher than that for the general population due to accidents, suicide and sudden unexpected death (Meador, 2006) There is also an elevated risk of mortality in a 
patient with seizures as the risk for death from drowning or as a result of a motor vehicle accident (NICE, 2012).

Nursing care for epileptic patients is a very important issue because they are exposed to numerous attended risks and complications. Nursing personnel must take special care to minimize that risk. The most important nursing intervention is to maintain adequate airway, breathing and circulation during the seizure and to prevent injury. Have an oral airway suction apparatus at bedside all times (Jerome et al., 2008).

Assessing the patient is an important responsibility of the nurse for the patient with seizure episode and accurately documents the events. Any alterations in behavior preceding the seizure and the characteristics of the episode, such sensory- hallucinatory phenomena (e.g., an aura), motor effects (e.g., eye movements), and alterations in consciousness, and postictal state are noted and recorded (Stafstrom \& Rho, 2004).

Subject And Method.

Research design

A descriptive cross-sectional research design was used in this study.

\section{Study setting}

The study was carried out at the Neurological Outpatient Clinic of Assuit University Children Hospital.

\section{Sample: Type of sample}

A quota sample was used in this study. The total number of parents with epileptic children was 400 parents in the previously mentioned setting and the total number of children for the present study was 408 children because some parents had two or more children with epilepsy.

- The sample size was calculated by using the following: using the Epi Info 2000 statistical package. The calculation was done using the expected frequencies of the different risk factors among cases at $99 \%$ confidence interval. The sample size was calculated using the following equation: When the total population is greater than 10000 , statistics suggest that:

$$
N=\frac{Z^{2} p q}{\mathrm{D}^{2}}
$$

$\mathrm{N}=$ the desired sample size (when the population is greater than 10000).

$\mathrm{Z}=$ the standard normal deviation, usually set at 1.96 (or more simply at 2.0).

$\mathrm{D}=$ degree of desire accuracy usually set at 0.05 .

$\mathrm{P}=$ the proportion in the target population estimated to have a particular characteristic. If there is no reasonable estimate, then use 50\% (0.05).

For example, if the proportion of a target population with a certain characteristic is 0.05 , the $\mathrm{z}$ statistics is
1.96 (2.0), and we desire accuracy at 0.05 , then the sample size is

$$
N=\frac{Z^{2} p q}{\mathrm{D}^{2}}=\frac{2^{2} \times 5 \times 5 \times 100 \times 100}{5 \times 5 \times 10 \times 10}=400 \text { Parents }
$$

Tool of the study

An interview questionnaire was developed by the researchers for the collection of data. It was based on a review of related literature. And include tow tools as the following:

\section{Tool 1 it include three parts}

Part one

Socio-demographic data for parents and their children according to Abed el-Twaab, (2004). The investigator modified the item of income according to the rate of inflation and increase to be conforming.

\section{Part two}

Family history includes (5) questions such as a degree of relation and consanguineous. (26) Questions related to Child include present and past history, history of labor, onset and duration of disease, signs and symptoms, diagnosis, complication, regularity of tacking medication, side effect of medication ).

\section{Part three}

Parents' knowledge about epilepsy include (11) questions such as ( first time know disease - source of knowledge -definition - causes - signs and symptoms - problems which face children - their role in protection - medication - side effect) .

Tool 2: A Likert scale aimed to determine the attitude of parents with epileptic children. It consists of (18) statements about epilepsy. The responses were scored $(5,4,3,2$, and 1$)$, respectively on a Likert scale ranging from (strong agree - agree uncertain - disagree - strong disagree) It was modified by (Khalaf, 2009) to three points (agree uncertain and disagree). Items were scored $(2,1,0)$, respectively to assess parents' attitude towards epilepsy such as chance of education and married, prevalence of recovery from disease, role of genetic factors, presence of infection.

\section{Methodology: Administrative phase}

An official approval letter was obtained from the dean of the Faculty of Nursing, Assuit University to the director of the Assiut University Children Hospital and the director of Neurological Unit . The letter included a permission to carry out the study and explained the purpose and nature of the study.

\section{Pilot study}

A pilot study was carried out before starting data collection on (40) parents, who were excluded from the sample. The aim of the pilot study was to test the clarity of the tool and to estimate the time required to fill in the sheet. 


\section{Ethical considerations}

The researchers explained the purpose and nature of the study to each parent. The parent has right to agree or disagree to participation in the study; the consent to participate in the study was secured orally from every parent and participants were informed that the information obtained will be confidential and used only for the purpose of the study.

\section{Field work}

The researchers started to collect data from 19 October 2013 to the mid of May 2014. The researchers met the parents in the neurological clinic for three days per week. Each interview took about (15-20) minutes .The form was filled in by the researchers herself with every interviewed parent with the explanation of the purpose of the study for each one. Every answer from the parents was recorded according to the designed question in the sheet. The researchers filling (4:8) sheets were completed daily.

Statistical analysis: The obtained data were reviewed, prepared for computer entry, coded, analyzed and tabulated. Descriptive statistics (frequencies, percentage, mean and standard deviation) were done using the computer program SPSS \& Excel 2007.

\section{Scoring system}

Categorical variables were described by number and percent while continuous variables were described by mean and standard deviation. A chi-square test used to compare between categorical variables. A correlation test was used to compare differences in the distribution of frequencies between different factors. It was considered significant when ( $p$-values were less than 0.05). The total score for knowledge was (20). The scores of each item were summed up and then converted into a percent score (poor $=$ score $<50 \%$, pass $=$ score $50-70 \%$, good $=$ score $>70 \%$ )
The total score for attitude was (19). It was calculated by summing up the scores of each item and then converting them into a percent score. Parents' attitude was considered negative if the score was $\geq 60 \%$ and positive if the score was $<60 \%$ ). 


\section{Results}

Table ((1): Distributions of the studied parents with epileptic children regarding to their socio-demographic data at the Neurological Outpatient Clinic in Assuit University Children Hospital.

\begin{tabular}{|c|c|c|}
\hline Variable & \multirow{2}{*}{$\mathrm{N}=400$} & \multirow{2}{*}{$\%$} \\
\hline Parents & & \\
\hline \multicolumn{3}{|l|}{ Father age (years) } \\
\hline $20-<35$ & 73 & 18.25 \\
\hline $35-<50$ & 255 & 63.75 \\
\hline 50 and more & 72 & 18.0 \\
\hline \multicolumn{3}{|l|}{ Mother age (years) } \\
\hline $15-<30$ & 126 & 31.5 \\
\hline $30-<45$ & 248 & 62.0 \\
\hline 45 and more & 26 & 6.5 \\
\hline \multicolumn{3}{|l|}{ Father's education } \\
\hline Illiterate & 176 & 44.0 \\
\hline Basic education & 33 & 8.3 \\
\hline Secondary education & 123 & 30.8 \\
\hline University & 68 & 17.0 \\
\hline \multicolumn{3}{|l|}{ Mother's education } \\
\hline Illiterate & 232 & 58.0 \\
\hline Basic education & 12 & 3.0 \\
\hline Secondary education & 110 & 27.5 \\
\hline University & 46 & 11.5 \\
\hline \multicolumn{3}{|l|}{ Residence } \\
\hline Urban & 131 & 32.8 \\
\hline Rural & 269 & 67.2 \\
\hline \multicolumn{3}{|c|}{ Score of socioeconomic level } \\
\hline High & 27 & 6.7 \\
\hline Middle & 180 & 45.0 \\
\hline Low & 193 & 48.3 \\
\hline
\end{tabular}

Table (2): Distributions of the studied epileptic children regarding to their socio-demographic characteristics at the Neurological Outpatient Clinic in Assuit University Children Hospital

\begin{tabular}{|c|c|c|}
\hline Variable & $\mathrm{N}=408$ & $\%$ \\
\hline \multicolumn{3}{|l|}{ Child age (years) } \\
\hline $1-<5$ & 188 & 46.0 \\
\hline $5-<10$ & 125 & 30.6 \\
\hline $10-18$ & 95 & 23.4 \\
\hline \multicolumn{3}{|l|}{ Gender of child } \\
\hline Male & 212 & 51.9 \\
\hline Female & 196 & 48.1 \\
\hline
\end{tabular}


Table (3): Distributions of children regarding their past history of labor and risk factors of epilepsy at the Neurological Outpatient Clinic of Assuit University Children Hospital.

\begin{tabular}{|c|c|c|}
\hline Past history & No $=408$ & $\%$ \\
\hline \multicolumn{3}{|l|}{ Time of labor (according to term) } \\
\hline Full-term & 319 & 78.2 \\
\hline pre-term & 89 & 21.8 \\
\hline \multicolumn{3}{|l|}{ Type of labor } \\
\hline Normal & 232 & 56.9 \\
\hline Cesarean Section & 157 & 38.4 \\
\hline Vento's & 19 & 4.7 \\
\hline \multicolumn{3}{|l|}{ Risk factor } \\
\hline Present & 373 & 91.4 \\
\hline Not present & 35 & 8.6 \\
\hline Types of risk factors \# & $\mathrm{N}=373$ & \\
\hline -Fever & 182 & 45.2 \\
\hline -Jaundice & 159 & 39.3 \\
\hline -Not cry post labor immediately & 83 & 20.3 \\
\hline -Cyanosis & 82 & 20.2 \\
\hline - Seizures & 52 & 13 \\
\hline -Trauma of child & 49 & 12.1 \\
\hline - Meningitis & 32 & 8 \\
\hline - Headaches & 30 & 7.5 \\
\hline - Drowsiness & 23 & 6.1 \\
\hline - Brain heamorge & 14 & 3.5 \\
\hline - Chickenpox & 14 & 3.5 \\
\hline - Measles and other diseases & 19 & 4.75 \\
\hline Onset jaundice after labor & $\mathrm{No}=159$ & \\
\hline - One day : three day & 131 & 82.4 \\
\hline - Four day : week & 27 & 17.0 \\
\hline - week : month & 1 & 0.6 \\
\hline \multicolumn{3}{|l|}{ Duration of jaundice } \\
\hline - $1: 14$ days & 83 & 53.2 \\
\hline$-15: 28$ days & 53 & 32.7 \\
\hline - $29:$ and more & 23 & 14.1 \\
\hline Incubator Need for treat jaundice & No $=159$ & $\%$ \\
\hline -Yes & 121 & 80.3 \\
\hline No & 38 & 19.7 \\
\hline
\end{tabular}

\# More than one answer 
Table (4): Distribution of the studied parents regarding to their family history of epilepsy

\begin{tabular}{|c|c|c|}
\hline Items & $\mathrm{No}=400$ & $\%$ \\
\hline \multicolumn{3}{|l|}{ Family history } \\
\hline Positive & 269 & 67.3 \\
\hline Negative & 131 & 32.7 \\
\hline \multicolumn{3}{|l|}{ Degree of relation, $\mathrm{N}=269$} \\
\hline First degree & 133 & 49.4 \\
\hline Secand degree & 117 & 43.5 \\
\hline Third degree & 19 & 7.3 \\
\hline \multicolumn{3}{|l|}{ Other family member suffer from epilepsy } \\
\hline Yes & 131 & 32.7 \\
\hline No & 269 & 67.3 \\
\hline \multicolumn{3}{|c|}{ Other family member suffer from other neurological disease } \\
\hline Nocturnal enuresis & 85 & 21.3 \\
\hline Headaches & 314 & 78.5 \\
\hline Mental retardation & 1 & 0.3 \\
\hline
\end{tabular}

Table (5): Distribution of the studied parents regarding to their knowledge about epilepsy

\begin{tabular}{|c|c|c|c|c|c|}
\hline \multirow{3}{*}{ Item } & \multicolumn{4}{|c|}{ Knowledge } & \multirow[t]{3}{*}{ P value } \\
\hline & \multicolumn{2}{|c|}{ Correct } & \multicolumn{2}{|c|}{ Incorrect } & \\
\hline & No. & $\%$ & No. & $\%$ & \\
\hline Definition of epilepsy & 127 & 31.75 & 273 & 68.3 & 0.833 \\
\hline Causes of epilepsy & 145 & 36.25 & 255 & 63.8 & 0.800 \\
\hline Problems facing the epileptic child & 335 & 83.75 & 65 & 16.3 & 0.040 \\
\hline Benefit of medication & 268 & 67 & 132 & 33.0 & 0.400 \\
\hline Side effect of medication & 49 & 12.25 & 351 & 87.8 & 0.060 \\
\hline
\end{tabular}

Table (6): Relation between parents' knowledge about epilepsy and socio-demographic characteristics

\begin{tabular}{|c|c|c|c|c|c|c|c|}
\hline & \multicolumn{6}{|c|}{ Knowledge level $\mathbf{N}=400$} & \multirow{3}{*}{ P. Value } \\
\hline & \multicolumn{2}{|c|}{ Poor } & \multicolumn{2}{|c|}{ Pass } & \multicolumn{2}{|c|}{ Good } & \\
\hline & No. & $\%$ & No. & $\%$ & No. & $\%$ & \\
\hline Father's age & $\mathrm{N}=284$ & & $\mathrm{~N}=113$ & & $\mathrm{~N}=3$ & & \\
\hline $20-<35$ & 44 & 29.8 & 28 & 24.6 & 1 & 33.3 & 0.705 \\
\hline $36-<50$ & 173 & 57.5 & 80 & 70.2 & 2 & 66.6 & \\
\hline 50 and more & 67 & 9.9 & 5 & 4.4 & 0 & 0.0 & \\
\hline Mother's age & $\mathrm{N}=283$ & & $\mathrm{~N}=114$ & & $\mathrm{~N}=3$ & & \\
\hline $15-<30$ & 77 & 23.6 & 48 & 42.1 & 1 & 33.3 & 0.247 \\
\hline $30-<45$ & 182 & 66.4 & 64 & 56.1 & 2 & 66.6 & \\
\hline 45 and more & 24 & 10 & 2 & 1.8 & 0 & 0.0 & \\
\hline Residence & $\mathrm{N}=238$ & & $\mathrm{~N}=114$ & & $\mathrm{~N}=3$ & & \\
\hline Urban & 61 & 21.6 & 67 & 58.8 & 3 & 100.0 & $<0001 *$ \\
\hline Rural & 222 & 78.7 & 47 & 41.2 & 0 & 0.0 & $<0.001^{*}$ \\
\hline Father's education & $\mathrm{N}=283$ & & $\mathrm{~N}=114$ & & $\mathrm{~N}=3$ & & \\
\hline IIliterate & 156 & 55.3 & 20 & 17.5 & 0 & 0.0 & \\
\hline Basic education & 28 & 9.9 & 5 & 4.4 & 0 & 0.0 & $<0001 *$ \\
\hline Secondary education & 80 & 28.4 & 42 & 36.8 & 1 & 33.3 & 0.001 \\
\hline University & 19 & 6.7 & 47 & 41.2 & 0 & 0.0 & \\
\hline
\end{tabular}




\begin{tabular}{|c|c|c|c|c|c|c|c|}
\hline & \multicolumn{6}{|c|}{ Knowledge level $N=400$} & \multirow{3}{*}{ P. Value } \\
\hline & \multicolumn{2}{|c|}{ Poor } & \multicolumn{2}{|c|}{ Pass } & \multicolumn{2}{|c|}{ Good } & \\
\hline & No. & $\%$ & No. & $\%$ & No. & $\%$ & \\
\hline Mother's education & $\mathrm{N}=283$ & --- & $\mathrm{N}=114$ & --- & $\mathrm{N}=3$ & --- & \\
\hline IIliterate & 202 & 71.6 & 30 & 26.3 & 0 & 0.0 & \\
\hline Basic education & 9 & 3.2 & 3 & 2.6 & 0 & 0.0 & \\
\hline Secondary education & 63 & 22.3 & 46 & 40.4 & 1 & 33.3 & $<0.001 \%$ \\
\hline University & 9 & 3.2 & 35 & 30.7 & 2 & 66.7 & \\
\hline Score Socio-economic level & $\mathrm{N}=320$ & --- & $\mathrm{N}=62$ & --- & $\mathrm{N}=18$ & --- & \\
\hline Low & 179 & 57.1 & 14 & 12.3 & 0 & 0.0 & \\
\hline Middle & 139 & 32.7 & 40 & 43.0 & 1 & 33.3 & $<0.001 *$ \\
\hline High & 2 & 10.2 & 8 & 42.8 & 17 & 66.7 & \\
\hline
\end{tabular}

Chi-square test $(x 2)=0.425$

*Statistically significant difference at $p<0.001$

Table (7): Relation between level of parents' attitude towards epilepsy and socio-demographic characteristics $(\mathbf{N}=\mathbf{4 0 0})$.

\begin{tabular}{|c|c|c|c|c|c|}
\hline & \multicolumn{4}{|c|}{ Attitude level } & \multirow{3}{*}{ P. value } \\
\hline & \multicolumn{2}{|c|}{ Negative } & \multicolumn{2}{|c|}{ Positive } & \\
\hline & No. & $\%$ & No. & $\%$ & \\
\hline Father's age & $\mathrm{N}=340$ & --- & $\mathrm{N}=60$ & --- & \\
\hline $20-<35$ & 54 & 14.3 & 19 & 31.7 & 0.298 \\
\hline $35-<50$ & 216 & 62.3 & 39 & 65 & \\
\hline 50 and more & 70 & 23.4 & 2 & 3.3 & \\
\hline Mother's age & $\mathrm{N}=340$ & $\begin{array}{ll}-- \\
-\end{array}$ & $\mathrm{N}=60$ & $\begin{array}{ll}-- \\
\end{array}$ & \\
\hline $15-<30$ & 95 & 28.5 & 31 & 51.7 & $0.034 *$ \\
\hline $30-<45$ & 219 & 63.2 & 29 & 47.4 & \\
\hline 45 and more & 26 & 8.3 & 0 & 0.0 & \\
\hline Residence & $\mathrm{N}=340$ & --- & $\mathrm{N}=60$ & $\begin{array}{ll}-- \\
\end{array}$ & \\
\hline Urban & 101 & 30.0 & 30 & 50.0 & \multirow{2}{*}{$<0.001 *$} \\
\hline Rural & 239 & 70.0 & 30 & 50.0 & \\
\hline Father's education & $\mathrm{N}=336$ & --- & $\mathrm{N}=64$ & --- & \\
\hline Illiterate & 160 & 55.6 & 16 & 26.7 & \multirow{4}{*}{$<0.001 *$} \\
\hline Basic education & 28 & 9.0 & 5 & 8.3 & \\
\hline Secondary education & 101 & 25.0 & 22 & 36.7 & \\
\hline University & 47 & 10.4 & 21 & 23.3 & \\
\hline Mother's education & $\mathrm{N}=340$ & --- & $\mathrm{N}=60$ & --- & \\
\hline Illiterate & 207 & 72.7 & 25 & 41.7 & \multirow{4}{*}{$<0.001 *$} \\
\hline Basic education & 10 & 1.3 & 2 & 3.3 & \\
\hline Secondary education & 90 & 22.2 & 20 & 33.3 & \\
\hline University & 33 & 3.8 & 13 & 21.6 & \\
\hline Score Socio-economic level & $\mathrm{N}=340$ & --- & $\mathrm{N}=60$ & --- & \\
\hline Low & 203 & 53.0 & 10 & 16.7 & \multirow{3}{*}{$<0.001 *$} \\
\hline Middle & 108 & 32.5 & 30 & 50.0 & \\
\hline High & 29 & 14.5 & 20 & 33.3 & \\
\hline
\end{tabular}

Chi-square test $*$ Statistical significant difference at $p<0.001$ 


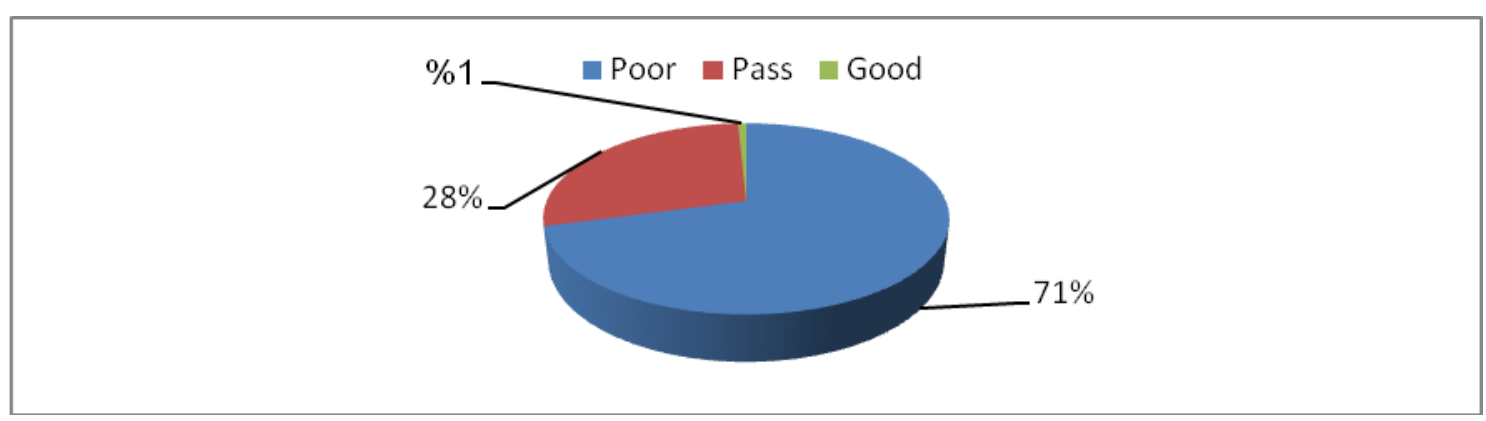

Figure (1): Distribution of studied parents regarding their knowledge about epilepsy.

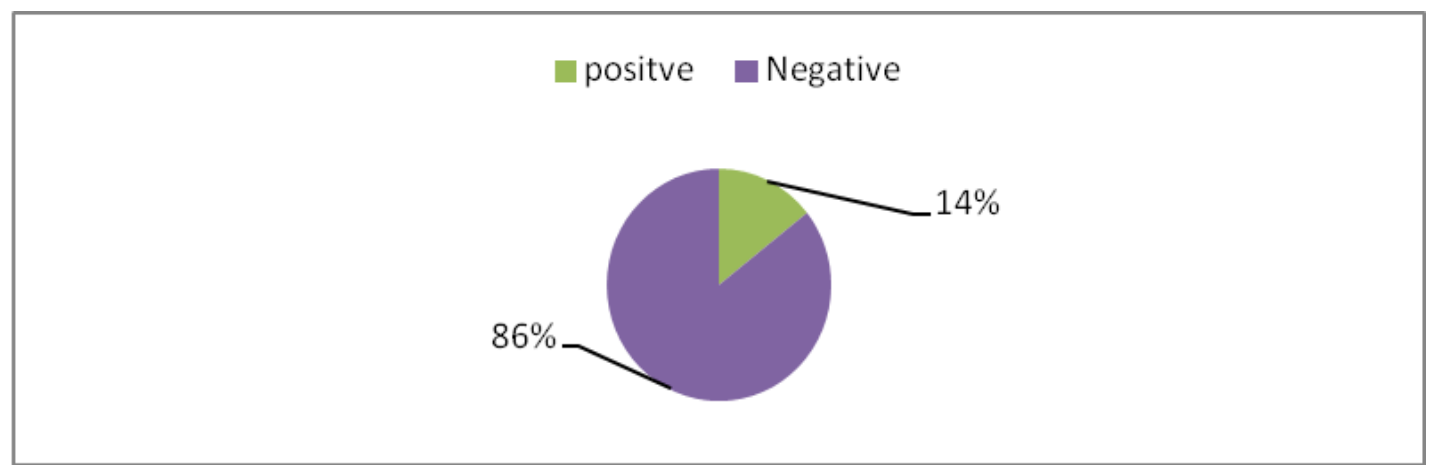

Figure (2): Distribution of studied parents regarding their attitude about epilepsy

Table (1): Two thirds $63.75 \%$ of the fathers were in the age group 36 to 51 years, Less than one fifth $18 \%$ of them were more than 52 years old. About two thirds $62 \%$ of the mothers were in the age group 31 to 46 years. and only $6.5 \%$ of them were more than 47 years old. As regards father's occupation, two thirds $65.75 \%$ of them had manual work, and $2.25 \%$ are dead. As regards mother's occupation, more than three quarters $79.5 \%$ of them were housewives. Also, as for father's education $44.0 \%$ of the fathers were not educated and, $58.0 \%$ of the mothers were not educated. Regarding parents' residence, more than two thirds $67.2 \%$ of them live in rural areas. Regarding parents' social status, the present study shows that less than half of the parents $48.3 \%$ had low social standards.

Table (2): shows that more than two fifths $46 \%$ of the children were aged 1 to 6 years. $51.9 \%$ of the children were males and $48.1 \%$ were females.

Table (3): shows that three quarters of the children $78.2 \%$ had full-term and $56.9 \%$ of them had normal delivery. Regarding risk factors of epilepsy, the present study shows that $91.4 \%$ of the children had a past history of risk factors and 45.2 of them suffer from fever while $39.3 \%$ of them suffer from jaundice.

Table (4): shows that more than two thirds of the children $67.3 \%$ had positive family history and $32.7 \%$ had another member who had epilepsy in their family. Also 49.4 of them had first degree and $78.5 \%$ had a family history of headaches.

Table (5): shows parents' knowledge about epilepsy. The table reveals that more than two thirds of the parents $68.3 \%$ didn't know the definition of epilepsy, $63.8 \%$ didn't know the causes of epilepsy, and $33 \%$ didn't know the benefit of medication. Also the majority of them $87.8 \%$ didn't know the side effect of medication.

Table (6): shows the relation between parents' knowledge about epilepsy and their sociodemographic characteristics. It reveals that there is a significant difference between parents' education, occupation, socio-economic level, and their score of knowledge about epilepsy.

Table (7): shows the relation between level of parents' attitude towards epilepsy and sociodemographic characteristics. It was found that there is a significant difference between parents' education, occupation, socio economic level, and their score of attitude towards epilepsy.

figure (1): shows that less than three quarters of the studied sample $71.9 \%$ had poor knowledge about epilepsy.

Figure (2): illustrates that the majority of studied parents $84.8 \%$ had negative attitudes towards epileptic children. 


\section{Discussion}

Knowledge is a vital factor in improving the ability to cope successfully with epilepsy by minimizing its impact on social and psychological functioning. It also reduces stigmatization, both actual and perceived, that accompanies epilepsy. It an important factor in reducing the impact of seizures, potentially harmful self-management practices. Therefore increased knowledge may lead to an improvement in the quality of life not only for patients but also for their family care giver. (Tugba et al., 2009).

The present study aimed to assess knowledge and attitude of parents about epilepsy . The findings of the present study showed that the range of parents' ages was 15- 56 years and ages of children 0:17 years. $51.9 \%$ of children were males and $48.1 \%$ were females.

These results were supported by Farghaly et el., (2012) who carried out a study to assess the prevalence of childhood epilepsy in both sex in Upper Egypt, Al Kharga District and Al Quseir City, and found that $51 \%$ of the study sample were males and $49 \%$ were females. Also this study agreed with Hamdy., (2010), who investigated the prevalence of epilepsy in primary school children in El-Minia City, Egypt, and he found that the prevalence of epilepsy was higher in boys than in girls.

The present study showed that educated parents had better knowledge than uneducated parents. Moreover, less than a quarter of parents had university education, which accounted for their good knowledge. However, more than $55.3 \%$ of the fathers and $71.6 \%$ of the mothers were not educated, which accounted for their poor knowledge. The present study revealed that there was a significant relation between parents' knowledge and their education. It may be interpreted by the fact that parents are influenced by college opinion and view because they stay long time in university and meet different cultures. Moreover, these results agreed with Tugba et al., (2009) who carried out a study knowledge and quality of life of Turkish children with epilepsy and their parents. And found that there was a relationship between the parents' knowledge and level of education.

The result of the present study revealed that the majority of parents who had poor knowledge had low socioeconomic status and that there was a relation between social score and knowledge about epilepsy. It may be explained by the fact that among lowincome families, worry was increased whereas knowledge of epilepsy was decreased, compared with families with higher incomes. Inadequate income was also found to be correlated with a perceived lack of social support.
This result agreed with Hamdy., (2010) who found that the prevalence of epilepsy was higher among middle class and much higher among low socioeconomic class children.

Concerning residence, the present study shows that two thirds of the parents under study live in rural areas; while more than one third lives in urban areas. Also there was a significant relation between parents' knowledge and their residence. This result can be explained by the fact that in rural areas there is no good health care seizures and any special centers for care.

As regards the past history of the disease, the present study revealed that $21.8 \%$ of the children had preterm delivery and $38.4 \%$ of them were delivered by cesarean section C.S. Also less than half $45.2 \%$ of the children had a history of fever, $12.3 \%$ of them were exposed to trauma, $20.5 \%$ are cyanosed post labor and $17.25 \%$ of them had a history of infectious disease (meningitis, tetanus, T.B, Chickenpox). Hamdy (2010) stated that neonatal insult, febrile convulsions, consanguineous marriage in parents and family history of epilepsy were the commonest prenatal risk factors. History of febrile convulsions was found in $36.2 \%$ of epileptic children in our study. Less than one third $31 \%$ of the children had a positive consanguineous marriage between their parents and $25.8 \%$ had a positive family history of epilepsy. Bhalla et al., (2011) state that close relatives have a risk five times greater than that of the general population.

As regards the family history and degree of relations the present study revealed that two thirds of the studied sample $67.25 \%$ had a positive family history. It may be accounted for by the fact that culture is the most common cause of hereditary epilepsy. The results of this study are in line with the results of an study conducted by Hamdy, (2010) the percentage of consanguineous marriage in parents of epileptic children in our study was similar to Hammed et al., (1988).

Children with epilepsy have higher rates of attention deficit hyperactivity disorders (ADHD), learning disorders and behavioral problems, disruptive behavior and aggression (Jacobs et al., 2009). Refractory epilepsies can result in higher rates of cognitive decline than well controlled epilepsies (Lagae, 2006).

The findings of the present study showed that two thirds of the parents had poor knowledge about epilepsy, While $68.3 \%$ of them don't know definition of epilepsy and 63,8\% of them don't know causes of epilepsy, it may explained by low social economic status, illiteracy and not get health education programs about epilepsy. These results were supported by Shehata \& Mahran, (2011), who 
found that clear gaps in knowledge, regarding the cause of epilepsy.

Regarding the causes of children's reluctance to take medication (anti epileptic drugs) regularly, the present study revealed that $28.7 \%$ of parents stated that long period of using medications lead to irregularity of medication uses. Also $11 \%$ of them seen the medication is expensive and $17 \%$ seen their children not improve. These results were supported by Shehata \& Mahran (2011) we found that clear gaps in knowledge, particularly with respect to medication.

Also $57 \%$ of parents were prefer take medication while $43 \%$ of them not prefer their children take medication but think in religious men, herpes, cupping, ironing, needles china . It may be explained by poor knowledge's and the educational program from basic education not contains enough knowledge about epilepsy and adverse effect.

Regarding to the side effects of medication on the child health, the present study found that $12.1 \%$, $60.4 \%, 22.9 \%, 10.4 \%, 4.2 \%, 4.2 \%$ of the parents stated that long period of treatment lead to effects on the liver and kidney, sleep and drowsiness, addiction, toxicity, and sensitivity, respectively. The presence of side effects may be due to chemical substances in medication and long periods of use. The current result agreed with Faroke et al., (2003) who found that their Challenges with antiepileptic pharmacotherapy .These studies disagreed with Rauj et al., (2006), who found that more than two third of parents, $68 \%$ mentioned no side effects of the drugs.

Concerning the total score of the parents', knowledge about epilepsy the present study found that the majority of parents $(71.9 \%)$ were poor knowledge about epilepsy, While (21.6\%) of them were satisfactory, and only (6.5\%) of the parent's were good knowledge and this may be related to that correct information about their children wasn't prevalent among them.. It may be explained by physicians do not give them enough information to manage or live at peace with their condition the educational program from basic education not contain enough knowledge about epilepsy and adverse effect. These findings were similar to Nazarabadi, et al., (2006) who found parent's that had poor knowledge about epilepsy.

Regarding parents' attitude towards epilepsy, the present study revealed that the majority $(84.8 \%)$ of parents had negative attitude, while the minority $(15.2 \%)$ of parents had positive attitude. It may be explained by the extended family play important role to convince the community to accept epilepsy to children. The results of the present study revealed that there was significant relation between attitude and their knowledge.
This study agreed with Tugba et al., (2009) who found that throughout their lives, more than $60 \%$ of people with epilepsy often feel stigmatized by their disorder, and up to $70 \%$ of them feel discriminated against by society

\section{Conclusion}

The current study found a significant deference between parents' knowledge and attitudes as regards epilepsy. So the researcher suggests that a welldirected health educational program about the causes and management of epileptic seizures may improve the perception of epilepsy by parents.

\section{Recommendations}

Based on results of the present study the following recommendation suggest

1-Application of continuous health education programs for parents in different grades with emphasis primary health care services especially epileptic children care to improve the parents' knowledge and attitude.

2-Application of comprehensive health education programs about neurological disease and the importance of seizures care through different mass media especially T.V.

3-Child may also be assigned to special programs in their school curriculum for prevention of the neurological diseases specially epilepsy.

4-Specific programs such as preconception counseling and genetic counseling should be imparted and integrated in $\mathrm{MCH}$ program.

\section{References}

1. Abd El-twab, E., (2004): Socioeconomic scale, faculty of education, Assiut University.

2. Assuit University Hospital, neurological outpatient clinic statistical recorded, (2012, 2013).

3. Bennet-Back, O., Keren, A., \& Zelnik, N., (2011): Attention-deficit hyperactivity disorder in children with benign epilepsy. Pediatric Neurology, 44 (3), 187-192. .

4. Bhalla, D., Godet, B., Druet-Cabanac, M., \& Preux, P., (2011): "Etiologies of epilepsy: a comprehensive review." Expert Rev Neurother 11 (6): 861-76.

5. Duncan J., (2009): The current status of neuroimaging for epilepsy. Curr Opin Neurol;22:179-84.

6. Farghaly W., Nagiub H., Rageh T., Shehata G., Badry R., Badry N., Abdelmonem M., Abd Al Wareth A., Kandil M., (2012): Outlook for therapeutic success with Current Antiepileptic 
Drugs $\left(1^{\text {st }}\right.$ Scientific Conference of Assiut Neuropediatric Unit, 2014).

7. Fastenau, P., \& Shen, F., (2010): Academic Underachievement Among Children With Epilepsy: Proportion Exceeding Psychometric Criteria for Learning Disability and Associated Risk Factors. Journal of Learning Disabilities 41(3): 195 - 208.

8. Faroke G, Van Der M., van Huffelen A., van Nieuwenhuizen O., (2003): High resolution spatio-temporal EEG-MEG analysis of rolandic spikes. J Clin Neurophysiol; 21:84-95.

9. Hammed H., (1998): Statistical studies on epileptic patients attending the epilepsy clinics of Alexandria University Hospitals in the past ten years. Msc. Thesis in Neuropsychiatry, Faculty of Medicine, Alexandria University.

10. Hamdy, N., (2010): Prevalence of Epilepsy in Primary School Children in El-Mania City, Egypt, Egypt J. Neurol. Psychiatry. Neurosurg, Vol. 46 (1) - Jan

11. Jacobs, M., Lebland, G., Brooks-Kayal, Amy, Jensen, Frances, E., Lowenstein, Dan, H., Noebels, Jeffrey, L., Spencer, Dennis, D., \& John, W., (2009): Curing epilepsy: Progress and future directions." Epilepsy \& Behavior 14: 438 445.

12. Jerome Engel, J., Timothy A., \& Pedley, E., (2008): Epilepsy: a comprehensive textbook (2nd ed. ed.). Philadelphia: Wolters Kluwer Health/Lippincott Williams \& Wilkins. p. 483.

13..Khalaf S., (2009): knowledge, attitude and practice of mother about chicken pox. Thesis submitted for partial fulfillment of requirements for Master Degree in Community Health Nursing. Faculty of nursing in Assiut, P73.

14. Lagae, L., (2006): Cognitive side effects of anitepileptic drugs. The relevance in childhood epilepsy. Seizure 15: 235 - 241.

15. Lewis M., Hatton C., Salas I., Leake B., \& Chiofalo N., (2008): Impact of the children's epilepsy program on parents. Epilepsia ;32: 365-74.

16. Meador E., (2006): Awareness, understanding and attitudes towards epilepsy among Iranian ethnic groups. Seizure, 18(5):369-373.

17. National Institute for Health \& Clinical Excellence (2012): Classification of seizures and epilepsy syndromes". The Epilepsies: The diagnosis and management of the epilepsies in adults and children in primary and secondary care.
"Chapter 9: National Clinical Guideline Centre. pp. 119-129.

18. National Institute for Health \& Clinical Excellence (2012): Introduction. The Epilepsies: The diagnosis and management of the epilepsies in adults and children in primary and secondary care. Chapter 1National Clinical Guideline Centre. pp. 21-28.

19. Nazarabadi H., Rezaeetalab G., \& Dastfan F, (2006): Study of youths' knowledge, behavior, and attitude towards consanguineous marriages Iranian Journal Public Health, Vol. 35, No.3, pp.47-53.

20. Nice (2012): The epilepsies: diagnosis and management of the epilepsies in children and young people in primary and secondary care, National Institute for Clinical Excellence. Clinical Guideline 20.

21. Panayiotopoulos \& Chrysostomos P., (2011):Benign childhood epilepsy with centrotemporal spikes or Rolandic seizures. Benign Childhood Partial Seizures and Related Epileptic Syndromes. London: John LibbeyEurotext. pp. 33-100.

22. Rau J., May T., Pfaefflin M., Heubrock D., \& Petermann F., (2006): Education of children with epilepsy and their parents by the modular education program epilepsy for families (FAMOSES): results of an evaluation study. Rehabilitation ;45:27-39 ( In German)

23. Shehataa G., \& Mahranb D., (2011): Knowledge and attitude of epilepsy among secondary schools students (epileptic and nonepileptic) in Assiut city, Egypt. Epilepsy Res, 95: 130-135.

24.Stafstrom C., Zupec-Kania B., \& Rho J., (2004): Ketogenic diet and related dietary treatments. Epilepsia; 49(Suppl 8):1-133.

25. Tan, G., Thornby, J., Hammond, D., Strehl, U., Canady, B., Arnemann, K., \& Kaiser, D., (2009): Meta-analysis of EEG biofeedback in treating epilepsy. Clinical EEG and neuroscience : official journal of the EEG and Clinical Neuroscience Society (ENCS) 40 (3): 173-9.

26. Tugba H., Ayse S., Ali C., Sebnem S., Eda D., \& Kivilcim G., (2009): Do knowledge of, perception of, and attitudes toward epilepsy affect the quality of life of Turkish children with epilepsy and their parents? 3 (2): 11-18.

27. WHO, (2014): Epilepsy. Fact Sheets. World Health Organization. October 2012. Retrieved January 24. 